\title{
The Square as a Figural Concept
}

\section{O Quadrado como Conceito Figural}

\author{
Helena Bezgovšek Vodušek ${ }^{*}$ \\ Alenka Lipovec ${ }^{* *}$
}

\begin{abstract}
In the geometry research we operate with mental entities, which contain an image as an essential component. This helps us in thinking, but it often does not coincide with the formal definition. In many cases, flat shapes are represented only with a curve, a boundary, and not as a part of the plane, which can lead to a false conception of flat shapes. The purpose of the research was to clarify pre-service elementary teachers' $(\mathrm{N}=186)$ concept image in the case of a square, whether it is hollow or filled, and what role it plays in problem solving. Qualitative methodology, specifically thematic analysis, was used in order to analyze participants' responses to a specially designed task. Only a very small part of participants gave expected answers. The results showed that the preservice teachers' image of a square as a frame totally dominated the conceptual part of the figural concept of a square.
\end{abstract}

Key words: Geometry. Figural Concept. Mathematical Knowledge for Teaching. Van Hiele Levels. Preservice Teachers.

\section{Resumo}

Quando investigando em geometria, operamos com entidades mentais cujo componente essencial é uma imagem. Isto nos auxilia a raciocinar, embora freqüentemente não haja coincidência entre essa situação e a definição formal. Em muitos casos, figuras planas são representadas apenas por uma linha curva, uma fronteira, e não como parte do plano, o que pode conduzir a uma falsa concepção das formas. Nesta investigação interessa-nos especialmente a imagem do quadrado, quer seja vazia ou preenchida, e no papel que esta imagem desempenha na resolução de problemas. Os resultados aqui apresentados dizem respeito ao conceito-imagem, no caso do quadrado, de 186 futuros professores do Ensino Fundamental. Tais resultados foram obtidos a partir da análise das respostas desses professores a tarefas especificamente elaboradas, e mostram que a imagem de quadrado como "moldura" é dominante no conceito figural em questão.

Palavras-chave: Geometria. Conceito Figural. Conhecimento Matemático para Ensinar. Níveis de Van Hiele. Formação de Professores para o Ensino Fundamental.

\section{Introduction}

Geometry deals with space and its characteristics and relationships between objects in space, therefore it is present, so to speak, in all spheres of our life. It often supports other

\footnotetext{
* Master in Mathematics - Education at University of Maribor, Slovenia. Assistant at the Faculty of Education, University of Maribor, Slovenia. Address: Koroška cesta 160, 2000 Maribor, SI - Slovenia. E-mail: Helena.Bezgovsek@uni-mb.si.

** PhD in Mathematics at University of Maribor, Slovenia. Associate Professor at the Faculty of Education, University of Maribor, Slovenia. Address: Koroška cesta 160, 2000 Maribor, SI - Slovenia. E-mail: Alenka Lipovec@uni-mb.si.
} 
areas of mathematics. With respect to its scope and importance, the geometry is not awarded a sufficient number of hours in today's curricula (JONES, 2000), especially if compared to other areas of mathematics. The priority of school mathematics is still arithmetic.

Gonseth (1945, 1955 apud KUZNIAK; RAUSCHER, 2011) differentiates three paradigms of geometry depending on the degree of integration with the real world or space: a) natural geometry, b) natural axiomatic geometry, and c) formal axiomatic geometry. In primary and secondary education, only the first two play an important role. The natural geometry is about finding the validity of our perceptions of the physical and tangible world or space. Within this paradigm, an image, a picture, or a model can also serve as an argument. The natural axiomatic geometry is characterized by an axiomatic model of the real world. The axioms are closely linked to our perception of space and the image, the picture, or the model are no longer sufficient arguments. They only serve as a support in reasoning and proving, which must derive from axioms, definitions, or proven properties. Formal axiomatic geometry is separated from the real world or space, its key feature is a complete and consistent system of axioms. This paradigm of geometry is not introduced into studies before the undergraduate level, and even there it is done to a lesser extent. In the continuation, we will therefore discuss only the first two.

When researching within geometry (especially within natural axiomatic geometry) we deal with and manipulate mental entities called figural concepts, which reflect spatial characteristics (shape, position, quantity), as well as conceptual qualities such as ideality, abstraction, generality, and completeness (FISCHBEIN, 1993). Unlike other areas of mathematics, the research in the field of geometry is characterized by the fact that mental entities with which we operate include the image as an essential component. True meaning of the word circle in geometry, as it is used in thinking, cannot be narrowed down to a clear definition, but in thinking and reasoning we are often helped by the image of a circle. Also, due to the above conceptual qualities, geometric concepts have no real physical presence. In our reality, there are only 3-dimensonal objects, where dimension is defined as an covering/topological element. Thus, there is no real example of a point, a line, or a square. Even geometrical 3-dimensional objects, such as a cube, do not exist in reality precisely because of these qualities. We only have their physical or graphical models. So, a figural concept is an image which is completely controlled by the definition. (FISCHBEIN, 1993).

Let us compare the figural concept, which is typical in the area of geometry, with the conceptual definition by Tall and Vinner (1981), which is a formal definition negotiated in a 
broader mathematical sphere and a conceptual image which represents the whole individual's cognitive schema or concept. An ideal figural concept corresponds to their conceptual definition, while the mental image of the conceptual definition, i.e. the figural concept with all connotations, ambiguities, and uncertainties, corresponds to their conceptual image (FISCHBEIN, 1993). In consequence, Vinner and Tall, as well as Fischbein, point to differences between the conceptual definition or the ideal figural concept, respectively, and the individual's conceptual image or its mental figural concept, respectively. The first may be contained in the second, but in a momentary mental process of reasoning, only a part of the conceptual image is included and it is not necessary that this evoked image includes the formal definition. It is not rare that inconsistencies occur between the depiction of a geometric concept and a formal definition. Sometimes the image literally dominates the definition and thus, knowing only the formal definition does not contribute to learning (MATOS, 1999). Also, there may be differences in the selection of a paradigm. Within the paradigm of natural geometry, the findings derived from the image or the physical depiction of a concept, such as the measuring of the length of a square diagonal, being acceptable and valid. Whereas, within the paradigm of natural axiomatic geometry, to which the figural concept specifically relates, it is necessary to consider axioms and formal definitions, and the picture or the model can only be of help, though they are no longer a sufficient argument (KUZINAK; RAUSCHER, 2011).

After Piaget and Bruner, the new theory on the development of geometric thinking and concepts as well as in geometry didactics was set by the Duch Dina van Hiele-Geldof and Pierre van Hiele in the 50's decade of the last century. Their initial theory assumes that an individual's development in the field of geometry follows a discreet hierarchical sequence of levels. These levels are numbered differently in different sources, starting with 0 or 1 . Here we list the original characterization of the initial levels: level $0-$ "Figures are judged by appearance" (VAN HIELE, 1984, p. 245); level 1 - "Figures are bearers of their properties" (VAN HIELE, 1984, p. 245); level 2 - "Properties are ordered" (VAN HIELE, 1984, p. 245); level 3 - "Thinking is concerned with the meaning of deduction, with the converse of a theorem, with axioms, with necessary and sufficient conditions" (VAN HIELE, 1984, p. 246). In their later works it is possible to find higher levels, but they are not significant for initial geometry training. Clements et al. (1999) found that geometric thinking already exists before level 0 . He proposes a new level, i. e. the pre-recognitive level. At this level, the individual is 
still uncertain on identifying shapes, paying attention only to some of its properties. At this stage, for example, all closed and rounded shapes are recognized as a circle.

Regardless of the number of levels, what matters in van Hiele's findings is that there is a natural sequence of levels, which is partly independent of the teaching methods and that this achievement of levels is not biologically conditioned. The result of observation and thinking on the previous level becomes the object of manipulation on the next one. If the result of level 0 are classes of shapes (such as circles, triangles, ...), they become the object of research at level 1, where it comes to find the properties of each particular class object. Such a relationship between the levels prevents skipping them. Each level is characterized by its own vocabulary, which means that (good) communication between people who operate at different levels is made impossible. This is exactly what is important in the process of education. If a teacher keeps teaching geometry at a van Hiele level, which students do not attain and do not know the vocabulary for, symbols and relations between objects, such teaching is ineffective, because students do not know what the teacher is saying. Similarly, a teacher who expects answers at a van Hiele level, which is different from the student's one, cannot make sense of the students' responses (VAN HIELE, 1984).

Some subsequent studies have shown that achieving van Hiele levels also depends on the content and that it is not necessary for an individual to achieve the same (global) level for different contents (MAYBERRY, 1983; WU; MA, 2006). It may also be that the individual in reasoning or finding solutions simultaneously uses two or more consecutive levels, what probably depends on the complexity of the problem being solved (BURGER; SHAUGHNESSY, 1986; GUTIÉRREZ; JAIME; FORTUNY, 1991). Here, the degree of a lower van Hiele level is more complete (GUTIÉRREZ; JAIME; FORTUNY, 1991) and remains an important part of a student's cognitive schemata (MATOS, 1999). A higher degree of acquisition of a lower van Hiele level means a greater certainty of operating at this level and this can lead to reasoning at a lower level. In this case, a visual image can dominate the properties, which determine the shape such as in the following example:

Teacher: Doesn't it have three straight sides?

Child: Yes.

Teacher: And what else did you say triangles have to have?

Child: Three angles. It has three angles.

Teacher: Good! So ...

Child: It's not a triangle. It's upside down! (CLEMENTS; SARAMA, 2009, p. 123).

As early as 1986, Shulman pointed out that the mere subject knowledge is not enough for teaching. Among other things, he introduced the notion of pedagogical content 
knowledge. This includes the knowledge of how a particular content is presented to students in an appropriate way. Later, Ball, Thames and Phelps (2008) adapted Shulman's model to the field of mathematics and introduced the concept of mathematical knowledge for teaching (MKT), which includes, on one hand, pedagogical content knowledge (PCK), and on the other hand, subject matter knowledge. The first (i. e. PCK) is further divided into knowledge of content and students (KCS), knowledge of content and teaching (KCT), and knowledge of content and curriculum (KCC). Knowledge of the subject includes common content knowledge (CCK), which played an important role before Shulman (1986) and was the only one to be checked, and also specialized content knowledge (SCK) and horizon content knowledge (HCK). At this point, we shall not discuss in detail each category of knowledge necessary for effective teaching. Let us only mention that CCK is the knowledge of mathematics owned by the majority of educated people, which allows them to reliably perform mathematical operations. In doing this, one does not ask himself/herself why these procedures apply or work. Knowledge and understanding of the background of known and well-established algorithms is an example of knowledge which is unique to teaching and not tied to the knowledge of students or teachers, therefore it falls within the second category of subject matter knowledge, i. e. the SCK category. The KCS category combines knowledge of content with the knowledge of students' responses when faced with this content, their typical errors, misconceptions, etc. When it comes to teaching, it is very important that one possesses skills which link knowledge of content with knowledge of teaching (KCT). This category includes the knowledge which allows the selection of adequate initial tasks for a selected content, adequate and effective presentations, methods, tools, etc. The boundaries between categories cannot be clearly defined and one needs to be aware that the classification of knowledge is not unique and that it changes with teacher's professional development. When the teacher first encounters new thinking provided by a student, he must judge by himself/herself whether it is appropriate, whether it can be generalized, or whether it is only valid for a particular task. In this case we deal with SCK. When the teacher thinks it over, we can say that we deal with the knowledge of students, i. e. KCS. The remaining categories (HCK and KCC) are closely linked to the curriculum. It is about knowing the curriculum and being aware of how the contents within the curriculum are interconnected.

The knowledge of the van Hiele theory and its further improvements is thus an important part of PCK in the field of geometry. Not only is this the source of knowledge about the levels at which geometric thinking is developed, their characteristics, 
interdependence and possibilities of passing from one to another i. e. KCS, but it is also the source of advice for more effective teaching. It allows monitoring the progress and selection of activities which lead to higher levels of achievement. Teachers often underestimate the ability of students and their prior knowledge. They assume, for example, that students entering the school have no knowledge of geometry (CLEMENTS; SARAMA, 2009). Therefore, during schooling students' geometry knowledge spreads but in general it is not upgraded (TOMAS, 1982 apud CLEMENTS; SARAMA, 2000). Of course when emphasizing the PCK we should not forget that in order to teach successfully it is crucial to possess mathematical knowledge $(\mathrm{CCK})$, which is the foundation and a pre-requisite for knowledge of all the other categories of MKT. Weak subject knowledge causes unnecessary loss of valuable time in the classroom (BALL; THAMES; PHELPS, 2008). In teacher training programs there is not enough geometry and/or the content is not upgraded. The research concentrating on geometric knowledge of pre-service and in-service teachers has shown that their knowledge is at a low level. Many times they only know what was taught to them in high school (JONES, 2000). A large proportion of them does not even reach the van Hiele level required by the curriculum from students who are or will be taught by them (MAYBERRY, 1983; MASON; SCHELL, 1988). Consequently, we cannot expect their students to acquire satisfactory geometry knowledge. Therefore, improving the knowledge of geometry (CCK and SCK) together with the knowledge about the cognition of students in the field of geometry can significantly raise the geometry teaching level. Swafford, Jones and Thornton (1997) have found that teachers who attended a training program which included activities to improve the knowledge of geometry (CCK) and acquire the van Hiele theory, were much more confident (at the end of program they achieved higher van Hiele levels than before their inclusion in the program) and they did not avoid contents from geometry in teaching. Not only they devoted more time to geometry, but they also used more open approaches to teach and also included tasks that required knowledge belonging to these higher van Hiele levels.

As mentioned above, natural axiomatic paradigm of geometry is mostly present in school geometry, which is based on axioms that reflect our perception of real space, and on definitions and proven properties. However, it has long been known that there is no absolute definition of geometric objects. Definitions have been negotiated within a broader mathematical community. Thus, for a quadrilateral or, more generally, a geometric plane shape, it is necessary for some people that it is bounded by a simple curve, yet this is not a 
pre-requisite for others. Also, for some students a parallelogram is a special type of trapezoid, while it is not for others. Slovenian schools follow the principle from a solid to a point so they introduce flat shapes by imprints from boundary surfaces of solids, which corresponds to van Hiele level 0. Quite later on (if at all), their formal (complete) definitions are introduced, i. e. van Hiele Level 2. They are mostly defined with a super-notion. A square is usually defined as a flat shape, which..., or a quadrilateral which.... The concept of a square as quadrilateral is not introduced in the Slovenian curriculum until the $4^{\text {th }}$ grade, and even then only by the means of polygons. If the definition occurs, it is presented by the teacher. Students are only familiarized with it and do not create the definitions by themselves. De Villiers (1998) found that the independent creation of definitions of geometric concepts, by finding necessary and sufficient conditions, improves the understanding of figural concepts.

The notion of a flat shape remains formally undefined. The definition is thus based on prototype images. The images of prototypes, it is true, are filled when introduced, but they are later replaced with frames, polygonal lines or curves, because other aspects are important such as area, number of diagonals, internal angles, etc. The representation of shapes only with a curve, which limits the shape, is present not only in Slovenian materials for students and teachers, but can also be seen elsewhere as well and in research (e.g. CLEMENTS; SARAMA, 2009; KNIGHT, 2006; WU; MA, 2005). This creates a problem of distinction between the curve and the shape itself. In Slovenian language there are separate names for a boundary (“krožnica”, circumference) and a 2D shape (“krog”, circle). In everyday English, (also in textbooks and articles) the name circle is used for the boundary, as well as for the 2D shape, though in strict technical application the circle refers to the boundary, while the disk is used for the 2D shape. However, even in the Slovenian language there is a separate naming only in the case of the circle, while in the case of other plane shapes and curves we do not use different names. A widely accepted definition, such as for ellipse, refers to the curve, although it is also considered a shape because we calculate its area.

\section{Purpose of the research}

The problem of distinction between the flat shape and the curve, which limits it, has not been seen in literature. The results of the study by Wu and Ma (2005) would suggest that students are mostly baffled by the width of a line around a circle, while they do not mind it so much in the case of a quadrilateral and a triangle. The same is true for filled and hollow 
representations of shapes. The purpose of this article is to highlight the differences between the perception of shapes and curves of pre-service teachers in elementary education and to contribute to the understanding and knowledge of SCK in this target population. We shall limit ourselves only to a square, because we believe that it is a sufficiently representative example of a geometric shape, which is often perceived as a curve.

\section{Methodology}

The research involved Slovenian pre-service elementary teachers who have finished elementary mathematics and 4 years of compulsory high-school mathematics (560 hours ${ }^{1}$ ) prior to entering the faculty. In addition, all participants studying to be elementary teachers attended a 75-hour mathematics class. In many European countries students can choose the level of mathematics in high school. This means that Slovenian participants had had more hours of mathematics compared to their colleagues from other EU countries. TIMSS advanced 2008 showed good mathematical knowledge (Slovenian students achieved average results) of $40 \%$ of the total Slovenian population. With respect to this, it would be logical to expect the participants in our research to have a good CCK.

A single task was given in a virtual surrounding to 240 elementary school pre-service teachers studying at the Faculty of Education at the University of Maribor. The time for replying to the questionnaire was limited to one month and the achievement contributed to the final grade. We believe that motivation in solving this task was high.

We started from a task found in a Slovenian $4^{\text {th }}$ grade textbook. The assignment indirectly addresses different mutual positions of a square and a circumference ${ }^{2}$. Since a square is a flat shape, one sub-task is not solvable, which is unusual for school assignments. We wanted to know whether the pre-service elementary teachers would take into account the fact that a square is a plane shape and not just a frame, as normally presented in the materials. In order not to affect the results, we asked the participants how they would react to a particular pupil's answer.

The task given to participants of this study was as follows:

The following homework was given to the $4^{\text {th }}$ grade pupils:

Draw a circumference and a square in such way that they would have:

\footnotetext{
${ }^{1}$ This are school hours, one school hour is 45 minutes.

${ }^{2}$ In Slovenian language there is an expression ("krožnica") for a curve which divides the plane in the interior from the exterior of a circle. This expression was translated as circumference. It is important to note that "krožnica" is a geometric object, i.e. a curve, and not the length of that curve, which is the usual meaning for the circumference.
} 

a) One common point,
b) Two common points,
c) Four common points and
d) Eight common points.

The next day a pupil comes to you and tells you that she solved items a), b) and c) and that item d) does not have a solution. How would you respond to this pupil? Write your respond using no more than 200 words.

We choose a qualitative methodology. A thematic analysis was used in six phases as suggested by Braun and Clarke (2006). In the first phase we got familiar with the data by reading all pre-service teachers' answers and making some notes of our initial ideas. In the second phase, we generated initial codes that identified interesting features of the data that appeared important to the analyst. We organized data into meaningful groups according to these codes. In the next phase, i. e. the third phase, we searched for themes that were often broader. In the forth phase, we reviewed themes according to an internal homogeneity and an external heterogeneity. In the fifth phase, we named and generated definitions for each theme. In the last phase, we produced the report by providing excerpts of the participants' answers for each theme to illustrate themes and compare them with the relevant literature. Due to the nature of this qualitative research, the findings from this study are not for drawing generalization.

\section{Results}

One hundred eighty six $(77.5 \%)$ elementary pre-service teachers responded to this assignment. Our aim was to analyse whether they had realized that item d) could not be solved. Actually, the problems in the concept image could be observed already in items b), and c) if they accepted solutions as given on the left half of Figure 1. However, for these items there is a correct solution, which is presented on the right half of Figure 1. 


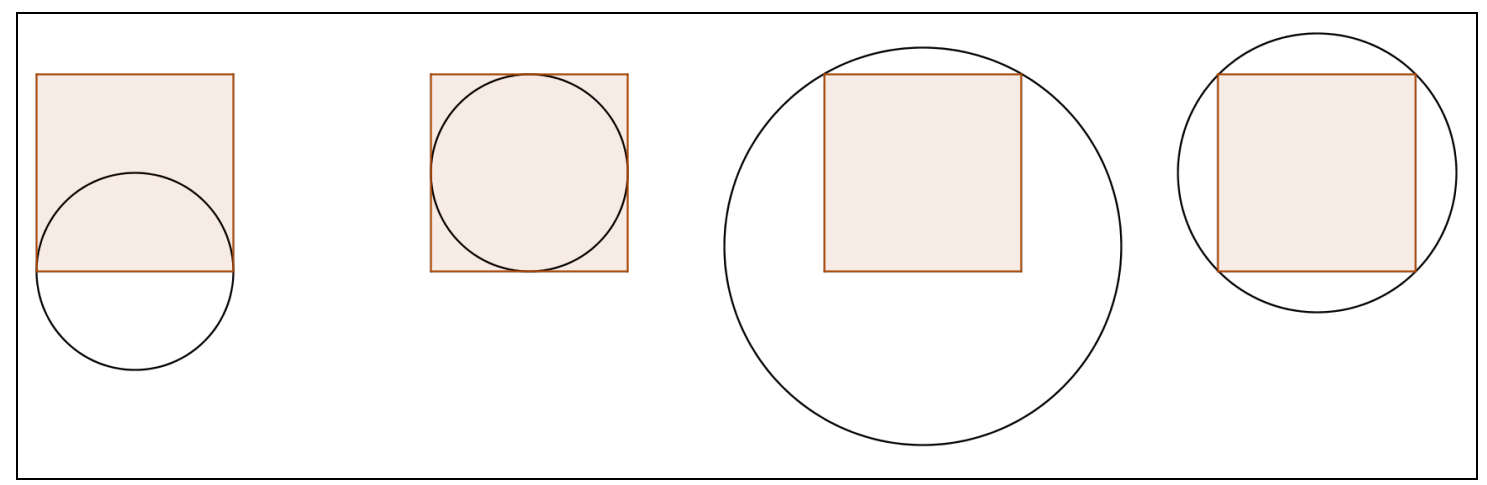

Figure 1 - Incorrect and correct drawings of solutions of items b) and c) Source: developed by the authors

We focused on item d) because it is the first item in which it is mathematically clear that the solution cannot be found. Pre-service teachers also provided detailed answers about this item.

We will first present the results of how the pupil's dilemma was considered. Was it considered as correct or incorrect? One hundred seventy four pre-service teachers $\left(93.5 \%^{3}\right)$ thought that item d) is solvable; only 11 teachers (5.9\%) claimed that the pupil's answer was correct. For one of the pre-service teachers it could be concluded that she did not understand the task, because it was answered that she would recalculate it once again.

In this section we will give a detailed analysis of the 11 teachers' answers who presumably could have firm mathematical knowledge.

Table 1 - Structure of answers of pre-service teachers who believe that item d) has no solution.

\begin{tabular}{|c|c|c|c|}
\hline $\begin{array}{l}\text { Item d) is } \\
\text { solvable } \\
\mathrm{N}(\mathrm{f} \%) \\
\end{array}$ & Code & $\begin{array}{c}\mathrm{N} \\
\mathbf{f} \%\end{array}$ & Description \\
\hline $\begin{array}{c}\text { YES } \\
174(93.5 \%)\end{array}$ & $\begin{array}{l}\text { Square } \\
\text { is a } \\
\text { frame }\end{array}$ & $\begin{array}{l}174 \\
93.5 \%\end{array}$ & \\
\hline \multirow{3}{*}{$\begin{array}{l}\text { NO } \\
11(5.9 \%)\end{array}$} & $\begin{array}{l}\text { Square } \\
\text { is not } \\
\text { hollow }\end{array}$ & $\begin{array}{l}3 \\
1.6 \%\end{array}$ & $\begin{array}{l}\text { "The square is a plane figure, which means that its interior is "full". I } \\
\text { will help the pupil to realize this by cutting a square out of a piece of } \\
\text { paper." }\end{array}$ \\
\hline & $\begin{array}{l}\text { Square } \\
\text { has } 4 \\
\text { vertices }\end{array}$ & $\begin{array}{l}4.2 \% \\
2.2 \%\end{array}$ & $\begin{array}{l}\text { "Item d) could not be solved since a square has only } 4 \text { vertices, an 8- } \\
\text { polygon would be needed." }\end{array}$ \\
\hline & Other & $\begin{array}{l}4 \\
2.2 \%\end{array}$ & $\begin{array}{l}\text { No understandable mathematical explanation about why item d) has } \\
\text { no solution. They focused on other aspects i.e. } \\
\text { "It is not necessary for all of the tasks to have a solution. Some of them } \\
\text { are unsolvable, but we also have to think them through. Item d) was given } \\
\text { to reinforce one's thinking." }\end{array}$ \\
\hline
\end{tabular}

Source: Developed by the authors

\footnotetext{
${ }^{3}$ Hereafter, if not said otherwise, we mean percentages of all who responded to the task (186).
} 
From Table 1 we could conclude that only 3 pre-service teachers $(1.6 \%)$ took into consideration that a square is a $2 \mathrm{D}$ shape and also contains points from its interior, not only those on the boundary. They do not see a square as a frame. These teachers, precisely, had shortly before had some experience with a similar task while they were preparing for a classroom lecture (which the objective was: A student is able to sort geometrical shapes according to their dimensions) as a part of their practical training. Even these 3 students showed some lack of understanding, since all three of them believed that only item a) was solvable. Two of them pointed out that only item a) is solvable and accompanied their argumentation with drawings similar to the drawings on the left half of Figure 1, while the third one misunderstood a square and presented a solution in which it was replaced by a block (rectangular prism).

The first result that can be therefore stated is that the (evoked) concept image of a square, drawn by (almost) all pre-service teachers included in the research, is a frame and not a filled figure.

The waste majority of pre-service teachers (174) declared the pupil's answer incorrect. One hundred thirty-one pre-service teachers (70.4\%) gave answers from which their drawing in item d) could be predicted. They presented the drawing or described it with words. Further, forty-one $(22.0 \%)$ pre-service teachers claimed that the drawing did exist, however they did not present it. Perhaps the most interesting solution that included the filled square was given by 3 pre-service teachers (1.6\%). Two of them proposed a paper cut-out model of a square and a circle as a teaching tool and accompanied their solution with the drawing shown in Figure 2. It seems that they were really unaware of discrepancies in their drawings. So, even as concrete representations as paper cut-out models, they have the potential to cause conceptual confusion for the pre-service teachers.

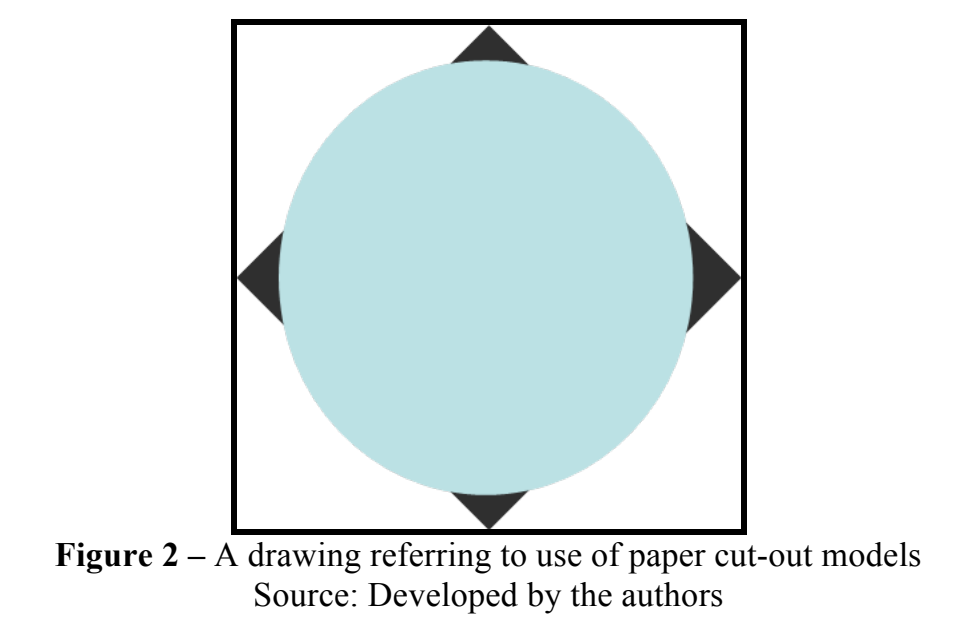


In the next section, the themes and codes with excerpts of the pre-service teachers' answers will be presented. Only the case where a square was treated as a frame will now be observed. The percentages mean the ratio of the participants who were convinced that item $\mathrm{d}$ ) had a solution and who also presented it with a drawing or in words, totalling 131 participants. It has to be noted that in the answers of some of the participants more than only one code or theme was found.

Table 2 - "Square is a frame" themes

\begin{tabular}{|c|c|c|c|}
\hline Theme & Code & $\mathbf{N}(\mathbf{f} \%)$ & $\begin{array}{c}\text { Excerpts of pre-service teachers' answers } \\
\text { illustrating the code }\end{array}$ \\
\hline \multirow{2}{*}{ Trial and Error } & $\begin{array}{l}\text { A different } \\
\text { number of points } \\
\text { of intersection } \\
\text { could be } \\
\text { achieved by } \\
\text { changing the size } \\
\text { of one of the } \\
\text { objects. }\end{array}$ & $58(44.3 \%)$ & $\begin{array}{l}\text { "First, I would ask her what would happen when we } \\
\text { reduce the circumference to a quadrilateral. How } \\
\text { many common points would they have? (I suppose the } \\
\text { answer would be zero.) I would, then, ask her to draw } \\
\text { this. Then I would ask her: 'What else can we do with } \\
\text { the circle? If we first reduce it, now we can ...' (... } \\
\text { enlarge it)." }\end{array}$ \\
\hline & $\begin{array}{l}\text { A different } \\
\text { number of points } \\
\text { of intersection } \\
\text { could be } \\
\text { achieved by } \\
\text { changing } \\
\text { positions of } \\
\text { objects. }\end{array}$ & $22(16.8 \%)$ & $\begin{array}{l}\text { "If the student would still not succeed (a square would } \\
\text { probably still be in the horizontal position), I would } \\
\text { emphasize that the square is not necessarily } \\
\text { horizontal. Thus, she would come to the desired result } \\
\text { with trying and reasoning." }\end{array}$ \\
\hline \multirow[b]{2}{*}{ Symmetry } & $\begin{array}{l}\text { Both centres of } \\
\text { gravity have to } \\
\text { coincide. }\end{array}$ & $39(29.8 \%)$ & $\begin{array}{l}\text { "I would first draw a square and then its centre. I } \\
\text { would then draw a circumference with the same centre } \\
\text { and a different radius until I found the right answer." }\end{array}$ \\
\hline & $\begin{array}{l}\text { The answer } \\
\text { includes the } \\
\text { limits of the size } \\
\text { of the object } \\
\text { suitable for } \\
\text { solution. }\end{array}$ & $14(10.7 \%)$ & $\begin{array}{l}\text { "The radius of the circumference should not be } \\
\text { smaller than the radius of the inscribed circumference, } \\
\text { because, in this case, the circumference would be too } \\
\text { small and there would not be any common points. /.../ } \\
\text { So, the radius has to be bigger than the radius of the } \\
\text { inscribed circumference and smaller than the radius of } \\
\text { the circumscribed one." }\end{array}$ \\
\hline \multirow{2}{*}{ Linearity } & $\begin{array}{l}\text { The square has } \\
\text { four sides/angles; } \\
\text { therefore there } \\
\text { have to be two } \\
\text { intersections at } \\
\text { each. }\end{array}$ & $34(26.0 \%)$ & $\begin{array}{l}\text { "First I would ask her how many sides a square has. } \\
\text { After she answers four, I would ask her how many } \\
\text { intersections each side must have to get } 8 \text { in common. } \\
\text { When she finds out that each needs } 2 \text { intersections } \\
\text { /.../" }\end{array}$ \\
\hline & $\begin{array}{l}\text { Item c) is a } \\
\text { starting point. } \\
\text { The number of } \\
\text { intersections in } \\
\text { item d) is two } \\
\text { times bigger. }\end{array}$ & $5(3.8 \%)$ & $\begin{array}{l}\text { "I would help her with questions: 'Look how you } \\
\text { solved item c). How many points are here? And how } \\
\text { many points are needed in item d)? How would you get } \\
\text { twice as many points? What about doubling each point } \\
\text { from item c)?" }\end{array}$ \\
\hline
\end{tabular}




\begin{tabular}{|c|c|c|c|}
\hline Theme & Code & $\mathbf{N}(\mathbf{f} \%)$ & $\begin{array}{c}\text { Excerpts of pre-service teachers' answers } \\
\text { illustrating the code }\end{array}$ \\
\hline \multirow[b]{2}{*}{ Analogy } & $\begin{array}{l}\text { With other 2D } \\
\text { shapes. }\end{array}$ & $12(9.1 \%)$ & $\begin{array}{l}\text { "We would try to find the answer together, maybe for } \\
\text { some other } 2 D \text { shapes. For example with two } \\
\text { rectangles. How would you place two rectangles to get } \\
8 \text { common points? Or two squares for a start. We } \\
\text { would make a comparison about how two rectangles } \\
\text { or two squares are positioned. Then I would leave her } \\
\text { to think about it and try solving the item again." }\end{array}$ \\
\hline & $\begin{array}{l}\text { With a line and a } \\
\text { circumference } \\
\text { ("known" } \\
\text { relations). }\end{array}$ & $4(3.1 \%)$ & $\begin{array}{l}\text { "Then I would ask her in what way a line segment and } \\
\text { an arc could be intersected (we take one side and a } \\
\text { quarter of a circumference). When do they not have a } \\
\text { common point? When do they have one common point } \\
\text { and when do they have two? If she knew this, I would } \\
\text { ask her how this is helping her to solve our problem. If } \\
\text { she figured out the solution by herself, the problem } \\
\text { would be solved." }\end{array}$ \\
\hline $\begin{array}{l}\text { Terminological } \\
\text { mistakes }\end{array}$ & $\begin{array}{l}\text { Naming a square } \\
\text { a cube, a } \\
\text { circumference a } \\
\text { circle, a shape a } \\
\text { solid or using } \\
\text { both as } \\
\text { synonyms. }\end{array}$ & $32(24.4 \%)$ & $\begin{array}{l}\text { "I would show them how a circle and a square look } \\
\text { like and would then try moving one and the other flat } \\
\text { shape. So, the children would be able to see what is } \\
\text { happening with the other solid or flat shape, when one } \\
\text { is getting bigger or the other is getting smaller." }\end{array}$ \\
\hline \multirow[t]{2}{*}{ Pedagogical } & $\begin{array}{l}\text { Giving the child } \\
\text { the opportunity } \\
\text { for further } \\
\text { explanation. }\end{array}$ & $(95 ; 71.0 \%)$ & $\begin{array}{l}\text { "I would ask her what caused the problem in the last } \\
\text { item. I would tell her to show me how she tried to solve } \\
\text { the item, what she used as help, and why she decided } \\
\text { that item d) had no solution." }\end{array}$ \\
\hline & Motivational & $(26 ; 19.8 \%)$ & $\begin{array}{l}\text { "I would tell her that item d) is solvable" or "I would } \\
\text { not immediately show her the solution" }\end{array}$ \\
\hline
\end{tabular}

Source: Developed by the authors

\section{Discussion}

Only when conflicting aspects are evoked simultaneously a cognitive conflict may occur. In our case, we believed that the task could be a trigger, however, only a very small part (less than 6\%) of the participants gave answers as we expected. According to Fischbein (1993) we could say that in solving this problem the pre-service teachers' image of a square as a frame totally dominated the conceptual part of the figural concept of a square, which was in the background and probably was not evoked at all. It seems that even if they intuitively modelled a square with a paper cut-out (see Figure 2), and we could predict that this representation would evoke the concept of a filled figure, their concept image of a square is still predominantly a frame. One of the methodical advices to teachers in the field of $2 \mathrm{D}$ shapes is to present a square either with paper cut-out models or with iconic representation with coloured/filled shapes. However, it seems that even this approach does not give satisfying results for all pupils neither for pre-service teachers. 
Attaining higher Van Hiele levels in the context of teaching is a pre-requisite for indepth knowledge of geometry, which falls within the scope of SCK. Based on the results, we may assume that elementary pre-service teachers did not achieve higher Van Hiele levels. Their thinking is mostly limited to the visual image of a square and rarely includes conceptual elements of this figural concept. This way of thinking is characteristic for the first two Van Hiele levels. Prospective teachers therefore do not reach the level expected by the curriculum for students who will be taught by them. The results are consistent with the results of other studies (e.g. PANDISCIO; KNIGHT, 2010; VAN DER SANDT, 2007).

The second reason for seeing a square as a frame could lie in the assumption that the solution of each mathematical task always exist. Students almost never ask themselves if a problem given to them is solvable or not and are ready to solve even unsolvable problems, if they are presented in ordinary classroom contexts. Reusser and Stebler (1997) found this characteristic in the area of contextualization. However, we believe that this belief is a consequence of a mathematic class culture and is spread out over all mathematical content areas, as it has been already proposed by Wertheimer (1945 apud REUSSER; STEBLER, 1997).

When we analyse the results more deeply we can find some other characteristics that the participants showed. It seems that they tend to believe that the pupil's knowledge is very low. Solving by trial is well spread, especially in early mathematics. It is a part of the Piagetian doctrine that children learn by first actively doing something in a more-or-less random way, and then hopefully learn from the consequences. It seems that the trial and error approach is more often used by students with low previous knowledge (KAPA, 2001). High frequency in the trial error theme in pre-service teachers' responses is consistent with this. They were convinced that the pupil was wrong due to her week knowledge, and according to this assumption the trial error strategy was appropriated for her.

The second is a "symmetry" belief or our internal preference for symmetric figures (ROSCH, 1973). Many young children in Clements' research (2004) did not recognize skewed triangles (non-isosceles ones). The participating pre-service teachers' belief that centres of gravity must coincide is a particular example of a commonly known problem. Students often use non given data in an assignment or transform it into a more prototypical one. For instance, when drawing a triangle, a sketch is often an equilateral triangle, which hinders the process of finding a solution. Mathematicians as a professional group also do not accept iconic proofs without accompanied axiomatic argumentation. In our cases, dealing 
with prototypical positions is probably a consequence of the solution of the prior item c) where a circumscribed (and for many, even inscribed) circumference which centre is in the middle of a square, is a suitable answer (see the last picture in Figure 1). In this place, we have to say that, if in the case of c) the centres of both objects having to coincidence, in case d) (when we look onto a square as a frame - obviously those participant did so), this is not necessary.

The next theme (connected to the second one) can be depicted as a linearity phenomenon (if there are 8 intersections on 4 edges, there should be 2 on each edge). The persistence of the linearity belief is already documented in the research by De Bock et al. (2007) and we give yet another example of it. De Bock et al. (2007) were considering mainly the linearity belief in the context of enlargement and reduction of figures and solids (the belief that multiplying the side of a square by 2 implies that its area is also multiplied by 2), however, they listed many other examples depicting the persistence of illusion of proportionality. Our research adds another example to this list.

Analogue thinking allows the transfer of knowledge from a known object (source object) to another, a new similar lesser-known object (target object). The key issue is to find similarities as well as differences in the structure between the source and the target object, which may not be outwardly obvious and sometimes requires considerable mental effort. At the same time, the knowledge of structures and substructures is an important part of SCK (BALL; THAMES; PHELPS, 2008; MORRIS; HIEBERT; SPITZER, 2009). In class, these analogies frequently occur, but a significant part is done by the teachers. Students do not really need to take a deeper mental effort towards analogue thinking, neither are they presented with (detailed) key similarities (RICHLAND; HOLYOAK; STIGLER, 2004). In terms of our work (if we assume that a square is dealt with as a frame), the reference to the analogous example of two squares or rectangles is appropriated. Because of their shapes, squares or rectangles, respectively, present a less demanding task than a circle, which is insensitive to rotations. As a starting point to solve the clue, the hint about the use of already researched (all) possible relative positions of a circumference or an arc and a line rarely appeared. There are two possible causes for this. Firstly, the participating pre-service teachers do not have sufficient knowledge and they did not recognize this analogy. Secondly, they are aware that it is a systematic approach which allows, when all options are considered, not only to find a solution, but also to justify that the solution does not exist. Knowing the students and the curriculum, we neither expected people of this age to solve the tasks in this way, nor to 
know enough about the relationship between a circumference and a straight line. As mentioned above, no essential part of analogue thinking is detected here: the search of the source object of analogies and similarities in their structure. In any case, we should not forget one important thing, namely that unfortunately subject knowledge (CCK and SCK) is inadequate in these cases.

In the Slovenian language a square and a rectangular prism have very similar names $k v a d r a t$ and $k v a d e r$. They are almost homophones and they are visually very similar, a square could be a rectangular prism's face. They are frequently used in a wrong way, but pre-service teachers should be aware of this problem and they are expected to use the terms properly. Using the term shape for a solid, a square for a rectangular prism or circumference for a circle (or vice versa) or using them as synonyms shows their lack of mathematical knowledge and also of PCK. Such an imprecise teacher's expression does not only result in an inaccurate students' expression but also in an inadequate development of students' geometric concepts. In the research done by Haghverdi, Semnami and Seifi (2012), which involved $7^{\text {th }}$ grade students, the fact of not setting an appropriate geometric shape turned out to be the most frequent error in solving geometrical word problems.

Because the purpose of this paper was the subject matter knowledge, in particular the specialized SCK, the analysis of the last theme is out of our range. It should be a good source of data for another study with the emphasis on the second part of MKT, the PCK.

\section{Conclusion}

In classroom materials, 2D shapes are commonly represented only with their boundaries as hollow objects. Next to hollow iconic representation, non-hollow real models are given to represent a concept of a plane figure (i.e. traffic signs, paper cut-outs...). In the initial phase of our research we asked 4 mathematicians (with $\mathrm{PhD}$ in mathematics) to provide a drawing of a square and a circumference intersecting in 2 points. All drawings were similar to the first picture in Figure 1. Only after the remark but a square is considered to be a plane figure they corrected the drawing. Our first conclusion, therefore, is that a square is also an example of a mathematical concept where the concept image and the concept definition usually do not coincide.

We cited several possible themes for which we believe that they show the problem of perception of a square. The fundamental finding of our paper is that problems of SCK of pre- 
service teachers lie in non-differentiation between 1D and 2D shapes. From the perspective of teaching, this differentiation is essential. We suspect that the problems are vertically transmitted in dimensions and that neuralgic points can be also traced in differentiating between $2 \mathrm{D}$ and $3 \mathrm{D}$ shapes. At the moment, when in the classroom we cut a box in the form of a rectangular prism to get a net, the question arises: Where is the prism now?. Our experience shows that pre-service and also in-service teachers provide different answers to this question. The belief that a $3 \mathrm{D}$ object can be transformed in a 2D shape is not uncommon. Their frequent response to the aforementioned question is namely: The prism has turned into a net. The problem is important because it indirectly reflects through the problematic of units of measurement. Teachers often observe that students in higher grades improperly select the unit of measurement for the volume or surface of solids, respectively. Another question also arises: whether there are difficulties only in the distinction of nearby dimensions.

Further research is needed, which would illuminate and enrich MKT pre-service and in-service teachers and consequently the knowledge of students. One of the possibilities is also to use the power of ICT and test the proposed imaginary situation in the environment of dynamic geometry software. For instance, in the GeoGebra environment flat shapes are not hollow by default what could encourage participants' awareness of the conceptual characteristic of $2 \mathrm{D}$ shapes.

\section{References}

BALL, D. L.; THAMES, M. H.; PHELPS, G. Content knowledge for teaching: What makes it special? Journal of Teacher Education, Washington, v. 59, n. 5, p. 389-407, 2008.

BRAUN, V.; CLARKE, V. Using thematic analysis in psychology. Qualitative Research in Psychology, London, v. 3, n. 2, p. 77-101, 2006.

BURGER, W. F.; SHAUGHNESSY, J. M. Characterizing the van Hiele Levels of Development in Geometry. Journal for Research in Mathematics Education, Reston, VA, v. 17, n. 1, p. 31-48, 1986.

CLEMENTS, D. H. Geometric and Spatial Thinking in Early Childhood Education. In: CLEMENTS, D. H.; SARAMA, J. (Ed.). Engaging young children in mathematics. Standards for Early Childhood Mathematics Education. London: LEA, 2004. p. 267-297.

CLEMENTS, D. H.; SARAMA, J. Young Children's Ideas about Geometric Shapes. Teaching children mathematics, Reston, VA, v. 6, n. 8, p. 482-488, 2000.

CLEMENTS, D. H.; SARAMA, J. Learning and teaching early math: the learning trajectories approach. New York: Routledge, 2009. 
CLEMENTS, D. H.; SWAMINATHAN, S.; ZEITLER HANNIBAL, M. A.; SARAMA, J. Young Children's Concepts of Shape. Journal for Research in Mathematics Education, Reston, VA, v. 30, n. 2, p. 192-212, 1999.

DE BOCK, D.; VAN DOOREN, W.; JANSSENS, D.; VERSCHAFFEL, L. The Illusion of Linearity. From Analysis to Improvement. Boston (MA): Springer, 2007.

DE VILLIERS, M. To teach definitions in geometry or to teach to define? In: CONFERENCE OF THE INTERNATIONAL GROUP FOR THE PSYCHOLOGY OF MATHEMATICS EDUCATION. $22^{\text {th }}, 1998$, Stellenbosch, South Africa, Proceedings... Stellenbosch, South Africa: University of Stellenbosch, 1998. p. 248-255.

FISCHBEIN, E. The theory of figural concepts. Educational Studies in Mathematics, Dordrecht, v. 24, n. 2, p. 139-162, 1993.

GUTIÉRREZ, A.; JAIME, A.; FORTUNY, J. M. An Alternative Paradigm to Evaluate the Acquisition of the van Hiele Levels. Journal for Research in Mathematics Education, Reston, VA, v. 22, n. 3, p. 237-251, 1991.

HAGHVERDI, M.; SEMNANI, A. S.; SEIFI, M. The Relationship Between Different Kinds of Students' Errors and the Knowledge Required to Solve Mathematics Word Problems. Bolema, Rio Claro (SP), v. 26, n. 42B, p. 649-665, Apr. 2012.

JONES, K. Teacher knowledge and professional development in geometry. In: BSRLM MEETING DAY CONFERENCE, $20^{\text {th }}, 2000$, Loughborough. Proceedings of the British Society for Research into Learning Mathematics. Loughborough: British Society for Research into Learning Mathematics, 2000. p. 109-114.

KAPA, E. A metacognitive support during the process of problem solving in a computerized environment. Educational Studies in Mathematics, Dordrecht, v. 47, n. 3, p. 317-336, 2001.

KNIGHT, K. C. An investigation into the van Hiele level of understanding geometry of preservice elementary and secondary mathematics teachers. 2006. 94 f. Dissertation (Master of Science in Teaching) - The Graduate School, University of Maine, Orono, ME, 2006.

KUZINAK, A.; RAUSCHER, J. C. How do teachers' approaches to geometric work relate to geometry students' learning difficulties? Educational Studies in Mathematics, Dordrecht, v. 77, n. 1, p. 129-147, 2011.

MAYBERRY, J. The Van Hiele Levels of Geometric Thought in Undergraduate Preservice Teachers. Journal for Research in Mathematics Education, Reston, VA, v. 14, n. 1, p. 58-69, 1983.

MASON, M. M.; SCHELL, V. Geometric understanding and misconceptions among preservice and inservice mathematics teachers. In: BEHR, M. J.; LACAMPAGNE, B. C.; WHEELER, M. M. (Ed.). Proceedings of the tenth annual meeting of the North American Chapter of the International group for the Psychology of Mathematics Education. KeBalb, Illi: Northern Illinois University, 1988. p. 290-296.

MATOS, J. M. Cognitive models for the concept of angle. 1999. $241 \mathrm{f}$. These (Doctor of philosophy) - Graduate Faculty of The University of Georgia, Athens, Gorgia, 1999.

MORRIS, A. K.; HIEBERT, J.; SPITZER, S. M. Mathematical Knowledge for Teaching in Planning and Evaluating Instruction: What Can Preservice Teachers Learn? Journal for Research in Mathematics Education, Reston, VA, v. 40, n. 5, p. 491-529, 2009. 
PANDISCIO, E. A.; KNIGHT K. C. An Investigation into the van Hiele Levels of Understanding Geometry of Preservice Mathematics Teachers. Journal of Research in Education, Eastern Educational Research Association, v. 20, n. 1, p.45-52, 2010.

REUSSER, K.; STEBLER, R. Every word problem has a solution-the social rationality of mathematical modeling in schools. Learning and Instruction, Oxford, v. 7, n. 4, p. 309-327, 1997.

RICHLAND, L. E.; HOLYOAK, K. J.; STIGLER, J. W. Analogy Use in Eighth-Grade Mathematics Classrooms. Cognition and instruction, Hillsdale, N.J., v. 22, n. 1, p 37-60, 2004.

ROSCH, E. Natural Categories. Cognitive psychology, San Diego, v. 4, n. 3, p. 328-350, 1973.

SHULMAN, L. S. Those who understand: Knowledge growth in teaching. Educational Researcher, Washington, D.C., v. 15, n. 2, p. 4-14, 1986.

SWAFFORD, J. O.; JONES, G. A.; THORNTON, C. A. Increased knowledge in geometry and instructional practice. Journal for Research in Mathematics Education, Reston, VA, v. 28, n. 4, p. 467-483, 1997.

TALL, D.; VNNER, S. Concept Image and Concept Definition in Mathematics with particular reference to Limits and Continuity. Educational Studies in Mathematics, Dordrecht, v. 12, n. 2, p. 151-169, 1981.

VAN HIELE, P. M. Summary of Pierre van Hiele's dissertation entitled: The problem of insight in connection with school children's insight into the subject-matter of geometry. In: FUYS, D.;

GEDDES, D.; TISCHLER, R. (Ed.). English translation of selected Writings of Dina van HieleGeldof and Pierre M. van Hiele. Brooklyn: City University of New York, Brooklyn College, 1984. p. 237-241.

VAN DER SANDT, S. Pre-service geometry education in South Africa: A typical case? Issues in the Undergraduate Mathematics Preparation of School Teachers, v. 1, p. 43-50, 2007.

WU, D. B.; MA, H. L. A study of the geometric concepts of elementary school students at van Hiele level one. In: CONFERENCE OF THE INTERNATIONAL GROUP FOR THE PSYCHOLOGY OF MATHEMATICS EDUCATION, 29 ${ }^{\text {th }}$, 2005, Melbourne. Proceedings... Melbourne: PME, 2005, p. 329-336, v. 4.

WU, D. B.; MA, H. L. The distributions of van Hiele levels of geometric thinking among 1st through $6^{\text {th }}$ graders. In: CONFERENCE OF THE INTERNATIONAL GROUP FOR THE PSYCHOLOGY OF MATHEMATICS EDUCATION, $30^{\text {th }}$, 2006, Prague. Proceedings... Prague: PME, 2006, p. 409-416. v. 5 . 